\title{
Ocular Immunology and Inflammation
}

\section{Ocular Manifestations and Visual Outcomes of Behçet's Uveitis in a Thai population}

\section{Kessara Pathanapitoon, Paradee Kunavisarut, Fa-Arun Saravuttikul \& Aniki Rothova}

To cite this article: Kessara Pathanapitoon, Paradee Kunavisarut, Fa-Arun Saravuttikul \& Aniki Rothova (2017): Ocular Manifestations and Visual Outcomes of Behçet's Uveitis in a Thai population, Ocular Immunology and Inflammation, DOI: 10.1080/09273948.2017.1351570

To link to this article: http://dx.doi.org/10.1080/09273948.2017.1351570

\section{曲 Published online: 11 Oct 2017.}

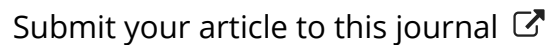

山 Article views: 18

Q View related articles ¿ك

View Crossmark data $\asymp$ 


\title{
Ocular Manifestations and Visual Outcomes of Behçet's Uveitis in a Thai population
}

\author{
Kessara Pathanapitoon, $\mathrm{MD}, \mathrm{PhD}^{1}$, Paradee Kunavisarut, $\mathrm{MD}^{1}$, Fa-Arun Saravuttikul, $\mathrm{MD}^{1}$, and \\ Aniki Rothova, $\mathrm{MD}, \mathrm{PhD}^{2}$ \\ ${ }^{1}$ Department of Ophthalmology, Faculty of Medicine, Chiang Mai University, Thailand and ${ }^{2}$ Department of \\ Ophthalmology, Erasmus Medical Centre, Rotterdam, The Netherlands
}

\begin{abstract}
Purpose: To report on ocular manifestations and visual outcomes of Thai patients with Behçet's Uveitis (BU).

Methods: We reviewed medical records of $50 \mathrm{BU}$ patients (31 males and 19 females). Ocular manifestations, treatment modalities, complications, and visual outcomes were registered.

Results: Ocular involvement was bilateral in $76 \%$ of patients, resulting in 89 affected eyes. Panuveitis and posterior uveitis were the most common types. Retinal vasculitis was noted in majority of affected eyes and specifically arteritis was noticed in $32 / 57(56 \%)$. Most patients received combination therapy of systemic corticosteroids and immunosuppressive agents (azathioprine $72 \%$ ). At final visit, VA $\leq 20 / 200$ was observed in 25 affected eyes $(28 \%)$. Risk factors for poor visual outcome were poor visual acuity at presentation $(p<0.001)$ and development of optic atrophy $(p=0.01)$.

Conclusions: Typical ocular manifestations of Thai patients with BU consisted of bilateral uveitis affecting posterior eye segment with high rate of complications and frequent visual loss.
\end{abstract}

Keywords: Behçet's uveitis, complications, ocular manifestations, Thailand, visual outcomes

Behçet's disease (BD) is a chronic, relapsing, systemic vasculitis of unknown etiology. Major sites of inflammation are the mucous membranes, skin, and the eyes. Behçet's Uveitis (BU) is typically characterized by recurrent episodes of posterior or panuveitis with occlusive retinal vasculitis. BU can lead to permanent vision loss and to various complications that arise either as a consequence of the inflammation and/or of its treatment. ${ }^{1}$ Long-term treatment with systemic corticosteroids, immunosuppressive agents as well as with novel biological drugs has been recommended to prevent the recurrent inflammation and visual loss. ${ }^{1-3}$

BU has a higher prevalence in the Mediterranean, ${ }^{4}$ Far and Middle Eastern countries., ${ }^{5,6}$ In Asia, BU was reported from Japan, ${ }^{7,8}$ Korea, ${ }^{9}$ Taiwan, ${ }^{10}$ China, ${ }^{11}$ and India. ${ }^{12}$ The prevalence of Behçet's disease in uveitis in Southeast Asia is not known. In Thailand, Behçet's disease was accounting for the cause of uveitis in about $6 \%^{13}$; however there are no data available on the clinical features and visual outcomes of BU in our country. Herein, we report on ocular manifestations, treatment modalities, complications and visual outcomes in BU patients in Thai population.

\section{METHOD}

We retrospectively reviewed medical records of $50 \mathrm{BU}$ patients (89 affected eyes) who had been treated in the uveitis clinic at Chiang Mai University Hospital between January 2006 and June 2016. All patients were classified according to the guidelines of International Study Group (ISG) for Behçet's disease. ${ }^{14}$

Medical records were reviewed for demographic data, location of uveitis at presentation, laterality, visual acuity (VA) at onset and at final visit, treatment modalities and development of the ocular complications as elevated intraocular pressure (IOP $>25 \mathrm{mmHg}$ ) and/or glaucoma, optic atrophy, retinal complications including cystoid macular edema,

Received 20 March 2017; revised 12 June 2017; accepted 3 July 2017

Address correspondence to Paradee Kunavisarut MD, Department of Ophthalmology, Faculty of Medicine, Chiang Mai University, 110 Intawaroros Road Chiang Mai 50200, Thailand. E-mail: pkunavis@med.cmu.ac.th; pkunavisarut@hotmail.com 


\section{K. Pathanapitoon et al.}

macular hole, macular scar and epiretinal membranes and retinal detachment (RD). RD was further classified into tractional, exudative, and rhegmatogenous $\mathrm{RD}$ (RRD).

Each patient underwent a full ophthalmic examination, including slit lamp biomicroscopy, tonometry and indirect ophthalmoscopy. Additional examinations as fluorescein angiography $(n=20)$ and optical coherence tomography $(n=42)$ were performed when required. Uveitis was classified according the anatomic localization recommended by the standardization uveitis nomenclature (SUN) working group. ${ }^{15}$

The term visual impairment was defined as VA of $<20 / 70$ and blindness was defined as VA of $\leq 20 / 200$ and/or a central visual field of $<10$ degrees. ${ }^{16}$

Statistical analysis was performed using descriptive statistical analysis with SPSS (version 16 software). We used Pearson $\times 2$ test or Fisher's exact test for categorical variables. Logistic regression analysis was also performed. $p$ values of $<0.05$ were considered statistically significant.

\section{RESULTS}

Our study included $50 \mathrm{BU}$ patients (89 affected eyes). There were 31 males and 19 females with a male: female ratio of 1.6:1. The mean age at onset of uveitis was $33 \pm 9$ years (range 9 to 56 years). The mean follow-up time was $48 \pm 36$ months (range from 3 to 120 months) (Table 1). No differences in the mean age at the onset of uveitis was noted between genders (male $=31.5 \pm 9.7$; range 9-56 years; female $=36 \pm 8.7$; range $19-48$ years $(p=0.09))$.

Bilateral ocular involvement was present in 38/50; $76 \%$ patients. Panuveitis and posterior uveitis were the most common ocular presentations, followed by intermediate and anterior uveitis with no difference between male and female patients. Retinal vasculitis was seen in $64 \%(57 / 89)$ of affected eyes and specifically arteritis was noticed in $32 / 57 ; 56 \%$. VA at presentation of $\leq 20 / 200$ was found in $39 \%(35 / 89)$ of affected eyes.

The majority of patients $(41 / 50 ; 82 \%)$ received a combination of oral corticosteroids and immunosuppressive agents including azathioprine $(88 \% ; 36 / 41)$, methotrexate $(27 \% ; 11 / 41)$ and cyclosporine $(24 \% ; 10 /$ 41). Six patients were treated with oral corticosteroids alone and three patients treated with oral corticosteroids, immunosuppressive agents, and infliximab.

One or more of ocular complications developed in $41 / 50(82 \%)$ patients $(79 / 89 ; 89 \%$ of affected eyes; Table 2) and complication rate was 0.2 per personyear. We found no difference between genders in development of complications (male 24/31 versus female 17/19; Pearson Chi-Square $p=0.282$ ). Cataract and macular lesions were the most frequent complications, occurring in $65 \%$ and $52 \%$ of affected eyes, respectively. RD was present in 4 of 89 eyes (4.5\%); of those, an exudative RD was diagnosed in 2 of 4 eyes, and RRD in 2 of 4 eyes.

One or more surgeries were required in 34 of 89 eyes $(38 \%)$. Cataract surgery was the most common surgery performed $(97 \% ; 33 / 34)$ followed by pars plana vitrectomy $(32 \% ; 11 / 34)$ and trabeculectomy (26\%; 9/34).

Patients with posterior uveitis developed more complications compared to non-posterior uveitis (11/ 12 versus 39/77; Pearson Chi-Square $p=0.008$ ) and patients who had been treated with oral corticosteroids alone developed more complications compared to regimens including also immunosuppressive drugs (3/6 versus 38/44; Pearson Chi-Square $p=0.03$ ).

Optic atrophy developed more frequently in patients older than 40 years compared to younger population (11/21 versus 11/68; Pearson Chi-Square $p<0.001)$. Logistic regression analysis showed that patients older than 40 year had $5.7 \times$ more chances of developing optic atrophy $(p<0.001 ; 95 \%$ CI, 1.9516.6).

TABLE 1. General characteristics of Behçet's uveitis in Thai patients.

\begin{tabular}{lc}
\hline Characteristic & Number of patients $\mathrm{N}=50$ \\
\hline Male-to-female ratio & $1.6: 1$ \\
Mean age at onset $( \pm$ SD; range; years) & $33 \pm 9(9-56)$ \\
Mean duration of follow up ( \pm SD; range; months) & $48 \pm 36(3-120)$ \\
Anatomical location of uveitis & $714 \%$ \\
- Anterior & $714 \%$ \\
- Intermediate & $1632 \%$ \\
- Posterior & $20 \%$ \\
Laterality & $40 \%$ \\
Bilateral & $3876 \%$ \\
Unilateral & $1224 \%$ \\
Blindness in at least one eye at final visit (at average follow-up of 48 months) & $2244 \%$ \\
Blindness in both eyes at final visit (at average follow-up of 48 months) & $48 \%$ \\
\hline
\end{tabular}


TABLE 2. Ocular complications of Behçet's uveitis per eye (at average follow-up of 48 months).

\begin{tabular}{lc}
\hline Complications & Number of eyes $(\mathrm{N}=89)(\%)$ \\
\hline Total number of eyes with at least one complication & $79(89)$ \\
Cataract & $58(65)$ \\
Macular complications & $46(52)$ \\
- Cystoid macular edema & $11(24)$ \\
- Macular hole & $2(4)$ \\
- Macular scar & $14(30)$ \\
- Epiretinal membrane & $17(37)$ \\
Retinal detachment (RD) & $4(4)$ \\
- Exudative RD & $2(50)$ \\
- Rhegmatogenous RD & $2(50)$ \\
Choroidal detachment & $2(2)$ \\
Optic atrophy & $22(25)$ \\
Ocular hypertension (IOP $>25 \mathrm{mmHg})$ & $19(17)$ \\
Glaucoma & $14(16)$ \\
Blind eyes & $25(28)$ \\
\hline
\end{tabular}

At final visit, VA of $\leq 20 / 200$ in 25 affected eyes $(28 \%)$ and VA of $\geq 20 / 70$ in 33 eyes $(37 \%)$. Bilateral blindness was found in 4 patients ( $8 \%$ ). No difference in blindness was noted between males and females (13/31 versus 9/19 Fisher's Exact Test $p=0.81)$.The risk factors for developing a blind eye included VA at presentation of $\leq 20 / 200(p<0.001)$ and development of optic atrophy $(p=0.01)$. Logistic regression analysis showed that patients with VA at presentation of $\leq 20$ / 200 had 17x more chances of developing a blind eye $(p<0.001 ; 95 \% \mathrm{CI}, 4.4-69.9)]$ and patients with optic atrophy had $5 \times$ more chances of developing a blind eye $(p=0.01 ; 95 \% \mathrm{CI}, 1.4-21.0)]$.

\section{DISCUSSION}

Our study demonstrates that complications and limited visual outcomes were common in in Thai patients with BU. Furthermore, we show that complications were more common in patients treated with corticosteroids solely compared to regimens including also immunosuppressive drugs. Patient with poor VA at presentation and who developed optic atrophy had a greater risk of having at least 1 blind eye.

The ocular manifestations of BU in Thai patients were similar to the previous reports as BU occurred more frequently in males, the involvement of posterior eye segment was typical and retinal vasculitis was observed in majority of patients. ${ }^{4,6,9-11}$ Ocular complications in BU are diverse and include commonly cataract (15-77\%), ocular hypertension $(14-31 \%)$ or glaucoma $(19 \%)$, macular edema (25-44\%), epiretinal membrane $(10-17 \%)$ and optic atrophy (8-24\%) and RD (1.4-11\%). ${ }^{4,6,11}$ In our series, almost all of the affected eyes (89\%) developed at least one complication. This could be due to the late initial presentation to ophthalmologist, recurrent inflammation and long-term use of corticosteroids together with the limited availability of the new immunomodulatory drugs. Patients with posterior uveitis developed more complications compared to non-posterior uveitis $(p=0.008)$.This illustrates a more severe character of BU with posterior segment involvement and might be also related to the need of more aggressive corticosteroids therapy leading to higher prevalence of glaucoma and cataract. Prevalence of cataract of $65 \%$ (58/89) is similar to the results from China (75\%), ${ }^{11}$ but much higher than from Saudi Arabia, where prevalence of cataract in BU was reported to be $15 \%$ with a follow-up of 8 years. ${ }^{6}$ In our series, optic atrophy and macular scars were the major causes of irreversible complications. We found no difference in development of complications and blindness between genders, whilst Turkish and Taiwan studies reported a significantly higher proportion of complications in male patients. ${ }^{4,10}$ (Table 3).

Study from two referral centers in England and in Australia found that male sex, unilateral disease, and left eye involvement increased the risks of severe visual loss at 5 and 10 years. ${ }^{17}$ Another study from Japan indicated a significant association between poor visual outcome and having more than three inflammatory attacks per year, severe vitreous opacities and exudates within the retinal vascular arcades. ${ }^{18}$ In our series, we found that also poor visual acuity at presentation and development of optic atrophy was the risk factors of poor visual outcomes.

Our study, in which oral corticosteroids and immunosuppressive therapy were the primary management of BU patients and only very limited number of patients used biologic drugs, we found that VA improved in $11 \%$ of patients, $28 \%$ developed blind eye and less than $50 \%$ of patients had VA better than $20 / 70$.Higher rate of complications was observed in patients who had been treated with oral corticosteroids alone compared to patients receiving also immunosuppressive drugs $(p=0.03)$. This observation underlines the need for immunosuppressive medications in BU and suggests than monotherapy with 
TABLE 3. Summary of previous reports on clinical features of Behçet's uveitis.

\begin{tabular}{|c|c|c|c|c|c|c|}
\hline $\begin{array}{r}\text { Country } \\
\text { (Year) }\end{array}$ & Present & Turkey $^{4} 2004$ & China ${ }^{11} 2006$ & Taiwan $^{10} 2008$ & Korea $^{9} 2015$ & Saudi Arabia ${ }^{6} 2015$ \\
\hline Number of patients & 50 & 880 & 437 & 227 & 56 & 132 \\
\hline (Number of eyes) & (89) & (1567) & $(691)$ & $(414)$ & (83) & $(232)$ \\
\hline Male:Female & $1.6: 1$ & $2.1: 1$ & $2.7: 1$ & $1.6: 1$ & $1.4: 1$ & $3.4: 1$ \\
\hline Mean follow-up time (years) & 4 & NA & 4 & 4 & 2 & 8 \\
\hline Mean age at onset of uveitis (years) & 33 & 30 & 30 & 31 & 34 & 37 \\
\hline \multicolumn{7}{|l|}{ Location of uveitis } \\
\hline - Anterior & $14 \%$ & $11 \% *$ & $\begin{array}{l}3 \% \text { in males } \\
17 \% \text { in females }\end{array}$ & $7 \% *$ & $17 \% *$ & $8 \%$ \\
\hline - Intermediate & $14 \%$ & NA & NA & NA & 0 & $3 \%$ \\
\hline - Posterior & $32 \%$ & $29 \% *$ & NA & $22 \% *$ & $28 \% *$ & NA \\
\hline - Panuveitis & $40 \%$ & $60 \% *$ & $\begin{array}{l}76 \% \text { in males } \\
50 \% \text { in females }\end{array}$ & $69 \% *$ & $55 \% *$ & $89 \%$ \\
\hline Retina vasculitis (eyes) & $64 \%$ & $89 \%$ & $32 \%$ & NA & NA & $52 \%$ \\
\hline \multicolumn{7}{|l|}{ Complications (eyes) } \\
\hline - Cataract & $65 \%$ & $38.5 \%$ & $77.4 \%$ & NA & NA & $15 \%$ \\
\hline - Elevated intraocular pressure & $21 \%$ & $13.8 \%$ & $31.4 \%$ & NA & NA & NA \\
\hline - Glaucoma & $16 \%$ & NA & NA & NA & NA & $19 \%$ \\
\hline - Macular edema & $12 \%$ & $44.5 \%$ & $38.2 \%$ & NA & $25 \%$ & NA \\
\hline - Epiretinal membrane & $19 \%$ & $17 \%$ & $9.6 \%$ & NA & NA & NA \\
\hline - Optic atrophy & $25 \%$ & $23.6 \%$ & $16.2 \%$ & NA & NA & $8.2 \%$ \\
\hline - Retinal detachment (RD) & $4 \%$ & $1.4 \%$ & $10.7 \%$ & NA & NA & $9.4 \%$ \\
\hline - Exudative RD & $50 \%$ & NA & $87 \%$ & & & $50 \%$ \\
\hline - Tractional RD & 0 & & $30 \%$ & & & $41 \%$ \\
\hline - Rhegmatogenous RD & $50 \%$ & & $14 \%$ & & & $9 \%$ \\
\hline \multicolumn{7}{|l|}{ Treatment } \\
\hline - Oral corticosteroids & $94 \%$ & $80 \%$ & NA & $53 \%$ & $78 \%$ & $93 \%$ \\
\hline $\begin{array}{l}\text { - Immunosuppressive agents } \\
\text { - Azathioprine }\end{array}$ & $72 \%$ & $30 \%$ & $\begin{array}{l}\text { NS(most common } \\
\text { cyclosporine and } \\
\text { chlorambucil) }\end{array}$ & $11 \%$ & NA & $49 \%$ \\
\hline - Cyclosporine & $20 \%$ & $10 \%$ & & $31 \%$ & $27 \%$ & $74 \%$ \\
\hline - Methrotrexate & $22 \%$ & 0 & & $5 \%$ & NA & $5 \%$ \\
\hline - Cyclophosphamide & 0 & $28 \%$ & & $7 \%$ & NA & 0 \\
\hline - Chlorambucil & 0 & $2 \%$ & & $4 \%$ & NA & 0 \\
\hline - Biologics & $6 \%$ & 0 & & 0 & 0 & $9 \%$ \\
\hline $\begin{array}{l}\text { Visual acuity at final visit } \\
\leq 20 / 200 \text { of affected eyes }\end{array}$ & $28 \%$ & $16 \%$ & $20 \%$ & $20 \%$ & NA & $22 \%$ \\
\hline
\end{tabular}

*Per eye

NA: not available; NS: non specific

corticosteroids is not adequate. Previous studies in pre-biologics era demonstrated that the visual prognosis in BU was generally poor with prevalence of blindness of $20-50 \%,{ }^{2,4,10,11,17,19-22}$ which are similar to our results. Interestingly, the rate of complications was much higher in our BU patients compared to Saudi Arabia, despite the similar usage of biologic drugs. ${ }^{6}$ This difference might be explained by a higher prevalence of late stages in our predominantly rural population. The high prevalence of cataract $(65 \%$ vs $15 \%$ in Saudi Arabia) might be speculatively explained by a higher dose or longer duration of corticosteroid medication. In addition, the choice of specific immunosuppressive agents can also play a role, as cyclosporine was more often used in Saudi Arabia than in Thailand ( $74 \%$ vs $20 \%)$. Cyclosporine might be associated with a better control of inflammation in BU than azathioprine, which was mainly used in our series. In Thailand, the availability of expensive medications is limited and available only for scarce patients. Treatment with biologics, given either as monotherapy or as add-on therapy, improved the visual prognosis with prevalence of blindness of less than $10 \%{ }^{2,3}$

Limitations of our study include its retrospective character, limited number of patients with variable follow-up time and a possible selection bias towards more severe cases, but this is relevant to all studies from tertiary referral centers.

In conclusion, our study demonstrates that BU in a Thai population is characterized by posterior or panuveitis commonly associated with retinal vasculitis (especially arteritis) and a high rate of complications and frequent visual loss. 


\section{DECLARATION OF INTEREST}

The authors report no conflicts of interest. The authors alone are responsible for the content and writing of the paper.

\section{Notes on contributors}

$\mathrm{KP}, \mathrm{PK}, \mathrm{FS}, \mathrm{AR}$ designed the study; KP, PK, FS, AR prepared the clinical protocol; KP, PK did the clinical study; KP, PK, FS, AR analyzed data; KP, PK, AR wrote and edited initial drafts; All authors reviewed the final draft

\section{REFERENCES}

1. Deuter CM, Kotter I, Wallace GR, Murray PI, Stubiger N, Zierhut M. Behçet's disease: ocular effects and treatment. Prog Retin Eye Res. 2008;27:111-136.

2. Takeuchi M, Kezuka T, Sugita S, et al. Evaluation of the long-term efficacy and safety of infliximab treatment for uveitis in Behçet's disease: a multicenter study. Ophthalmology. 2014;121:1877-1884.

3. Figus M, Posarelli C, Albert TG, Talarico R, Nardi M. A clinical picture of the visual outcome in adamantiadesBehçet's disease. Biomed Res Int. 2015;2015:120519.

4. Tugal-Tutkun I, Onal S, Altan-Yaycioglu R, Huseyin Altunbas H, Urgancioglu M. Uveitis in Behçet disease: an analysis of 880 patients. Am J Ophthalmol. 2004;138:373-380.

5. Khairallah M, Accorinti M, Muccioli C, Kahloun R, Kempen $\mathrm{JH}$. Epidemiology of Behçet disease. Ocul Immunol Inflamm. 2012;20:324-335.

6. Arevalo JF, Lasave $\mathrm{AF}, \mathrm{Al}$ Jindan $\mathrm{MY}$, et al. Uveitis in Behçet disease in a tertiary center over 25 years: the KKESH Uveitis survey study group. Am J Ophthalmol. 2015;159:177-184.

7. Tanaka R, Murata H, Takamoto M, et al. Behçet's disease ocular attack score 24 and visual outcome in patients with Behçet's disease. Br J Ophthalmol. 2016;100:990-994.

8. Muhaya M, Lightman S, Ikeda E, et al. Behçet's disease in Japan and in Great Britain: a comparative study. Ocul Immunol Inflamm. 2000;8:141-148.

9. Chung YR, Lee ES, Kim MH, Lew HM, Song JH. Changes in ocular manifestations of Behçet disease in Korean patients over time: a single-center experience in the 1990s and 2000s. Ocul Immunol Inflamm. 2015;23:157-161.
10. Chung YM, Lin YC, Tsai CC, Huang DF. Behçet's disease with uveitis in Taiwan. J Chin Med Assoc. 2008;71:509-516.

11. Yang P, Fang W, Meng Q, Ren Y, Xing L, Kijlstra A. Clinical features of Chinese patients with Behçet's disease. Ophthalmology. 2008;115:312-318.

12. Rohatgi J, Singal A. Ocular manifestations of Behçet's disease in Indian patients. Indian JOphthalmol. 2003;51:309-313.

13. Pathanapitoon K, Kunavisarut P, Ausayakhun S, Sirirungsi $\mathrm{W}$, Rothova A. Uveitis in a tertiary ophthalmology centre in Thailand. Br J Ophthalmol. 2008;92:474-478.

14. Criteria for diagnosis of Behçet's disease. International study group for Behçet's disease. Lancet. 1990;335:10781080.

15. Jabs DA, Nussenblatt RB, Rosenbaum JT, Standardization of Uveitis Nomenclature Working G. Standardization of uveitis nomenclature for reporting clinical data. Results of the First International Workshop. Am J Ophthalmol. 2005;140:509-516.

16. Organization WH. Consultation on development of standards for characterization of vision loss and visual functioning. WHO report 2003. http://whqlibdoc.who.int/hq/ 2003/WHO_PBL_03.91.pdf.

17. Taylor SR, Singh J, Menezo V, Wakefield D, McCluskey P, Lightman S. Behçet disease: visual prognosis and factors influencing the development of visual loss. Am J Ophthalmol. 2011;152:1059-1066.

18. Takeuchi M, Hokama H, Tsukahara R, et al. Risk and prognostic factors of poor visual outcome in Behçet's disease with ocular involvement. Graefes Arch Clin Exp Ophthalmol. 243:1147-1152.

19. Cingu AK, Onal S, Urgancioglu M, Tugal-Tutkun I. Comparison of presenting features and three-year disease course in Turkish patients with Behçet uveitis who presented in the early 1990s and the early 2000s. Ocul Immunol Inflamm. 2012;20:423-428.

20. Kaburaki T, Araki F, Takamoto M, et al. Best-corrected visual acuity and frequency of ocular attacks during the initial 10 years in patients with Behçet's disease. Graefes Arch Clin Exp Ophthalmol. 2010;248:709-714.

21. Khairallah M, Attia S, Yahia SB, et al. Pattern of uveitis in Behçet's disease in a referral center in Tunisia, North Africa. Int Ophthalmol. 2009;29:135-141.

22. Zierhut M, Saal J, Pleyer U, Kotter I, Durk H, Fierlbeck G. Behçet's disease: epidemiology and eye manifestations in German and Mediterranian patients. Ger J Ophthalmol. 1995;4:246-251. 